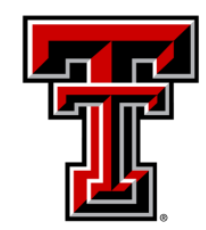

TEXAS TECH UNIVERSITY

Libraries"

\title{
Hungry, Hungry Gringos: Solving the Problems Posed by FEEDING TOURISTS
}

\section{The Texas Tech community has made this publication openly available. Please share how this access benefits you. Your story matters to us.}

\begin{tabular}{|l|l|}
\hline Citation & $\begin{array}{l}\text { Griffith, L. M. (2018), Hungry, Hungry Gringos: Solving the Problems } \\
\text { Posed by Feeding Tourists. Cult Agric Food Environ. } \\
\text { https://doi.org/10.1111/cuag.12223 }\end{array}$ \\
\hline Citable Link & $\underline{\text { https://hdl.handle.net/2346/82004 }}$ \\
\hline Terms of Use & $\underline{\text { CC-BY }}$ \\
\hline
\end{tabular}


Hungry, Hungry Gringos: Solving the Problems Posed by Feeding Tourists

Abstract: Tourist demand for food stuffs like delicate lettuce varieties that are ill-suited to the local environment are setting off a chain of reactions within the Cayo District of Belize. To meet demand, farmers are learning to grow these crops organically, synthesizing knowledge from a variety of sources in order to succeed in this new market. This paper takes readers through the experiences of villagers who work in several key sites of a luxury eco-resort - the restaurant, kitchen, storeroom, and organic farm - before turning to the implications for the village at large. Though catering to tourists' tastes is often treated as a form of neocolonialism, this case study examines the agency and creativity expressed by local community members as they adapt to this changing market.

I asked Ian, ${ }^{1}$ a Maya man in his mid-20s who works as a resort chef, what kinds of foods he cooks most often for guests. With a laugh, he shouted: "gringo food!" Gringo is a term used widely throughout Latin America but may have different meanings in different contexts. My friends in Belize mostly use it to describe tourists but have further explained that it can mean any wealthy person from the U.S. or Europe, typically - though not exclusively - of European descent. So, what is gringo food? "Anything fried," Ian told me. "And salads," he added shortly thereafter. A 'traditional' Belizean meal will typically include a side of coleslaw, often made with British-style salad cream. Entrée salads featuring organic vegetables on a bed of mixed

\footnotetext{
${ }^{1}$ Pseudonyms are used throughout for individuals and the name of the eco-resort. All other place names are real.
} 
spring greens and arugula are a recent addition to the local culinary scene and present interesting challenges for local farmers and restaurateurs.

This article is based primarily on two months of participant observation fieldwork and ethnographic interviews with farmers and resort staff in the Cayo District of Belize as well as an inductive analysis of restaurant reviews from TripAdvisor.com. This paper is part of a larger agenda of inquiry examining how Belize's eco-resorts overlap with agro-tourism contact zones (Pratt 1992) and to what degree transculturation leads to sustainable agricultural innovations that are in a dialogic relationship with local agricultural and environmental practices. In using the term 'agro-tourism contact zone' I am not focusing on agricultural tourism per se. Rather, I am pointing out that this particular contact zone is located at the nexus of tourism and agriculture. While some tourists may visit farms - particularly when staying at an eco-resort that promotes an organic garden/farm as one of its attractions- this is not the primary aspect of the agro-tourism contact zone that interests me. Rather, I am focusing on how tourists' culinary habits affect locals who must grow and prepare food for them, and vice versa. In other words, how does contact with foreigners lead to transculturation? This term was introduced in sociology in the 1940s and carried into literary studies in the 1970s, and it is still useful today to discuss the transformation - rather than the replacement or erasure - of local cultures that occurs through contact with others (Pratt 1992, see also see Sundberg 2006).

Pratt's original conception of the contact zone was used to describe the unequal, often coerced, and sometimes "chaotic" interactions that occur when populations that have been historically and geographically separated suddenly come together, as is the case with colonialism or tourism (Pratt 1992, 7). Belize was a British colony from 1862 through 1981. Colonialism instilled in Belizeans a preference for foreign foods; imports were seen as more prestigious than 
local, 'bush' foods, and even after Independence, nationalists were hard pressed to counter this narrative (Wilk 1999). Belize continues to be part of the British Commonwealth; however, Belizeans today are more connected to the United States than England, given the sheer numbers of Belizeans living in the U.S., the fixed exchange rate between the Belizean and U.S. dollars, and the vast numbers of U.S. citizens that visit Belize each year as tourists or live here as parttime residents (see Sutherland 1998). This American influence extends to how locals think about various food items and, it would seem, approaches to farming.

This paper focuses on one eco-resort in the Cayo District, which I have given the pseudonym Pepem Nah, walking readers through the experiences of workers in different units of the resort - especially the farm - before exploring the implications of the agro-tourism contact zone for the surrounding villages. The Cayo District boasts some of the nation's most impressive Maya ruins and is a hub for archaeo-tourism. Nearby villages that have been undergoing a revitalization of their Maya heritage (see Medina 2003) also make this an attractive location for guests interested in contemporary cultural tourism. The abundance of wildlife on the property and in the surrounding jungle make Pepem Nah ideal for tourists interested in nature as well, and the resort offers guided bird-watching sessions at daybreak. Cayo District appeals to many different kinds of tourists...all of whom must eat.

Approximately half of the workers at Pepem Nah are from San Antonio, the closest village as the crow flies. To save time and bus fare, many employees use a jungle footpath to navigate from their community down to the river and then canoe over to the resort. San Antonio village boasts some of the best farmers in the nation, and residents are consistently among the winners of country's Farmer of the Year award, which is voted upon by the Ministry of 
Agriculture and the National Agriculture and Trade Show Committee, ${ }^{2}$ making the relationship between Pepem Nah and this community particularly relevant to understanding the local agrotourism contact zone.

In this paper, I draw attention to the ways in which tourists' desire for (organic) salad affects workers at each stage in this production chain and highlight the creativity that comes out of these contact zones. Using friction as a metaphor for global processes, Tsing (2005) has argued that scholars must attend to these messy encounters because they shed light on processes of cultural change. Understanding why a particular menu item like a salad is so important to both tourists and those who serve them, as well as the food system in which such a transaction is embedded, necessitates going beyond simple calculations of supply and demand (see Fine, Heasman, and Wright 2002). The farmers, chefs, servers and other staff members at these resorts are both shaping and being shaped by an evolving conversation surrounding what to eat. For example, there is widespread agreement that organic vegetables are 'good' to eat, but people differ in the reasons they give for their preference. Many foreigners highlight the environmental benefits of eating organic whereas many of my Belizean friends focus on the health benefits, and at least one Belizean Mennonite farmer focused on the moral imperative to earn a living by the sweat of his brow instead of using a chemical shortcut. Salad is not like most imported foods, which have prestige simply because they are foreign. Salads occupy a hybrid place in the local culinary landscape; while the dish itself is not a traditional Belizean item, these fresh vegetables are unprocessed and - at least at the resort I am discussing - locally and organically grown.

\footnotetext{
${ }^{2}$ Farmers are nominated for this award by the District Agriculture Offices in all districts. Winners are announced shortly before the annual National Agriculture and Trade Show. Awards are given to the top male farmer, top female farmer, and top junior farmer.
} 
In the contemporary United States, organic produce is often held up as the pinnacle of ethical eating, a practice which involves a high degree of reflexivity and the conscious cultivation of tastes that are in accordance with one's values (Guthman 2003). When individuals carry these preferences with them on their travels, it presents both challenges and opportunities for local farmers. The farmers I discuss here face a number of constraints. They are told what to plant based on the kitchen's needs, which are informed by the tourists' desires, and must do so using organic techniques to meet the resort owner's mandate. ${ }^{3}$ At the same time, however, they express pride in their accomplishments in the field and are envisioning new futures for themselves inspired by what they have experienced in this contact zone. In a context such as this, no analysis of local food systems can be complete without considering the role tourists play in altering not only what is grown, but how those items are grown.

\section{Tourists’ Desires for Salad}

Although my ethnographic work did not include in-depth research with tourists at mealtime, I was able to ascertain why tourists are so investing in eating salad - something they could easily access at home - while in Belize by systematically analyzing reviews posted publicly on TripAdvisor.com. My sampling technique yielded 209 reviews of restaurants in San Ignacio that referenced salad in some way. Often this was just a brief mention that the restaurant

\footnotetext{
${ }^{3}$ The term 'organic' is used loosely in Belize. Farmers who wish to sell organic produce on the world market (e.g. cacao) have to conform to external standards. Vegetables being sold locally as organic, on the other hand, do not have to meet these standards. Therefore, there may be variation from one farm to the next in terms of what individual farmers/owners mean when they market something as organic. The farmers who work at Pepem Nah had little to no exposure to organic farming before they started working at eco-resorts, so their perception of what counts as organic is directly influenced by the practices and expectations of the farm managers and owners.
} 
served salad, which in and of itself is notable to anyone who visited the area regularly prior to 2010 or so. This approach provided insights into some of the reasons tourists choose salad over other options. Based on these reviews, it is clear that many visitors want a light and 'healthy' option, particularly after days or weeks of starchy dishes like rice and beans, a staple on most Belizean menus. Other tourists have dietary restrictions like being vegetarians, vegans, pescatarians, or needing gluten-free meals for medical reasons, all of which can make travel in Latin America challenging. For still others, eating local produce is part of the appeal of eating a salad, although none of these reviews acknowledged the difficulty farmers must have in growing delicate lettuce varieties or the fact that many of the vegetables featured in the salads are not well suited to the local environment.

When reviewers went into detail about particular salads they or a member of their party had ordered, most comments were positive. However, five reviewers expressed complaints about the lettuce in their salads. Two reviewers complained that the lettuce in their salad was iceberg. Although it is not clear if "they" refers to the server or the text on the menu, one reviewer wrote:

“...They talk up how all of the veggies are from their farm etc. But sadly it was an iceberg lettuce salad with my steak. Didn't think it merited the reviews..."

The salad in and of itself was not considered 'bad,' but iceberg lettuce was not what the reviewer expected when thinking about farm-fresh vegetables. Nowhere in the review is there any acknowledgement that the season, rainfall, demand, etc. might affect the availability of particular ingredients or that eating local sometimes necessitates being flexible in one's expectations. Furthermore, Caribbean and Central American destinations are often framed in such a way that tourists expect foods that conform to their preconceived ideas of 'freshness' (e.g. an abundance of tropical fruits, freshly caught fish and/or game, 'peasants' tending small-scale family farms, 
etc.), without any real knowledge of the social and historical circumstances that have shaped local agricultural and culinary practices.

Despite a few comments such as these, it was far more common for reviewers to make positive comments about their salads. Oftentimes, positive reviews of salad were tinged with surprise. One reviewer wrote "I wasn't expecting so much nutrition from a side salad!" Another described the restaurant they were reviewing as "[o]ne of few places in Belize with a good salad." Comments such as these as well as a review by another diner who wrote "we were happy to see so many vegetables" speak to my assertion that in Belize, salads are - or at least have been until recently - few and far between. A chef from San Francisco contrasted his Belizean salad with what had been on the menu elsewhere in Central America, writing that it was "[q]uite refreshing after 3 months of only iceberg in Mexico." Note that the chef does not specify the mix of lettuces actually used in the salads at this restaurant; rather, the absence of iceberg lettuce is what warrants praise.

Many tourists unfortunately see Belize's culinary scene as lacking. One reviewer on TripAdvisor even wrote that their experience at a particular restaurant in San Ignacio had been representative of all dining experiences in Belize: "great people, forgettable cuisine." In describing a newer restaurant that serves vegetables from Pepem Nah's farm, one reviewer wrote: "this is fine dining in San Ignacio and that's something that you just don't find in Belize." This preconception about Belizean cuisine helps to explain diners' surprise when they find a "crisp," "delicious" salad that is both "refreshing" and "filling." Even adventurous eaters whose reviews referenced eating street food and miscellaneous local fare expressed appreciation for the salads now so readily available in San Ignacio. 
Perhaps due to the growing influence of food writing and television programs (see Naccarato and Lebesco 2012), all of the descriptions drawn from TripAdvisor are particularly vivid and full of adjectives. In addition to some of the more predictable adjectives that reviewers could and do use to describe salads (i.e. fresh, organic, ${ }^{4}$ local), others focused on the texture or consistency of the vegetables (e.g. crisp, cold, refreshing), the aesthetics of the salad (e.g. chic and beautiful), the taste of the salad (e.g. delicious and flavorful), the size of the salad (e.g. ginormous and filling) or just general words of praise (e.g. awesome and heaven).

The more than 50 references to freshness in these 209 reviews are deserving of slightly more detailed attention. Interestingly, of these 56 comments, only four mentioned the word "farm" and only one mentioned the word "garden" in association with freshness. The concept of 'eating local' is clearly important to these reviewers; the use of local ingredients was mentioned 40 times and references to freshness and eating local co-occurred nine times in the reviews. However, diners may not link freshness and local provenience with farms and farmers. Writing about organic agriculture in California, Guthman $(2003,55)$ points out that while consumers may feel righteous based on their choice of organic salad mixes, the growing and harvesting of that produce "depends upon the same systems of marginalized labour" as do other segments of the (industrial) food system. Nor do these consumers tend to think about how the demand they created has led to farmers growing produce "out of place and out of season" (56). Similarly, the individuals writing reviews about Belizean salads cared that their food be locally sourced, but the

\footnotetext{
${ }^{4}$ Guthman (2003) traces the popularity of organic mixed salad greens to Alice Waters's restaurant in Berkeley, California. Other chefs in the area also adopted her preference for locally grown, organic produce and highlighted these features on their menus, especially when describing their salads. By the late 1980s, it was expected that cutting edge restaurants would all have organic salads on their menus. This long-term association between salad mixes and 'organic' production may have led to a conflation between the two terms in tourists' comments, and it should not be assumed that every salad served in Belize is organic.
} 
farmers themselves are only rarely mentioned in conjunction with discussions of local food production (see also Gray 2014).

Pepem Nah Resort: Making \& Serving Salads in the Contact Zone

In June of 2017, I spent approximately two weeks conducting participant observation at Pepem Nah's organic farm. Typical work at the farm included weeding, harvesting vegetables, foraging for wild seasonings, and tending to the compost as well as delivering, weighing and logging produce at the storehouse. I conducted informal interviews with all of the Englishspeaking farmers that worked during this period. ${ }^{5}$ Over the next six weeks, I conducted interviews with various farmers, sometimes at their farms and sometimes in public places. I also interviewed North American immigrants involved in a community supported agriculture (CSA) venture. I also did participant observation with this CSA, helping sort vegetables into individual portions and talking to members when they came to pick up their weekly shares. Sampling was purposive. I was introduced to some of these individuals by people who knew of my interests in organic agriculture and tourism; others came to my attention based on what they were selling at the market or by information they had posted on social media about farming in Belize.

In addition to the two-months of data collection I conducted in 2017, this paper is informed by more than seven years of engagement with the personnel of Pepem Nah. This luxury eco-resort has been a fixture of the community since the early 1980s. Like many resorts in the area, the owners - Kate and Lachlan - came to Belize from abroad, but are now well-integrated and highly regarded in the community. They gradually expanded their resort from a single thatch

\footnotetext{
5 The one monolingual speaker of Spanish was primarily responsible for tending to the goats, which was outside the scope of my project. Although we exchanged pleasantries, his experiences are not a foeal point of the work I am presenting here.
} 
cabana to its present form, which can accommodate roughly 100 guests on beautifully manicured grounds nestled deep in the rainforest. This couple divides their managerial duties. Lachlan has assumed primary responsibility for overseeing the farm, while Kate's attentions remain more focused on the running of the resort itself.

Pepem Nah is notable for many reasons, but I chose to conduct ethnographic research here because I witnessed Lachlan's management philosophy in action and was impressed by the autonomy he gave to his employees. This resort has also established various sustainability initiatives that align with my broader interests in how working at an eco-resort affects employees' personal commitments to the environment. While it would be a stretch to say that Pepem Nah is representative of Belizean hotels/resorts as a whole, it is fair to say that this resort contributes to setting local standards in the hospitality industry. The owners have won awards from the national tourism board, and innovations that start at Pepem Nah - like growing organic vegetables on-site - tend to be replicated at other resorts in the area. ${ }^{6}$

After driving 20 minutes down a dirt road riddled with potholes, the luxury of Pepem Nah and its open-air restaurant with white tablecloths and flickering candles is stunning. The accommodations consist of separate casitas [small houses] that range from approximately 300 to 1,200 USD per night. Breakfast is valued at 12 USD and lunch ranges from 15-20 USD per person. Dinner can be ordered a la carte, but the four-course prix fixe dinner (40 USD) is a particular highlight for many guests. To put this into perspective, the amount a tourist would spend on one day's worth of meals - excluding any drinks they might have at the bar - was equal

\footnotetext{
${ }^{6}$ There are no precise statistics on how many resorts in the area have their own gardens, although it is quite common in Belize, particularly at high-end resorts (e.g. Blancaneaux Lodge and Chan Chich Lodge) and niche resorts like Hidden Valley Inn, which has a coffee plantation on-site.
} 
to the cost of the home-improvement loan one farmer was struggling to repay at the time of my research.

Most guests arrive via the resort's shuttle service, but even if they do rent a car and come on their own, they are still likely to take at least some of their meals at the restaurant, especially breakfast and dinner. ${ }^{7}$ Periodically, members of the local community will also drive to the resort for a meal, typically to celebrate a special occasion. Granted, these tend to be professionals and others with disposable income from San Ignacio and Belmopan, and do not necessarily represent the average Belizean citizen who will rarely if ever dine in such an establishment. The resort restaurant is thus a key site within the agro-tourism contact zone, involving both front-of-house staff like servers as well as those working behind-the-scenes in the kitchen and bakery.

Servers have the opportunity to become ambassadors for local food-ways. Zara works the day shift and has been employed at the resort for more than 12 years. She lit up when she told me that her job gives her the opportunity to introduce guests to Belizean food. Although guests may initially be hesitant to try the local food, Zara says that once the guests have this realization they "let it go" and step outside of their comfort zone. Zara especially likes to highlight chaya, which she describes to guests as Mexican spinach. Chaya is a local leafy green that purportedly has anti-diabetic properties and also contains protein but must be cooked before eating because it contains low levels of cyanide. Zara tells tourists that it is very rich in iron, which they like, but they also enjoy the novelty of a new culinary experience.

Servers are an important link in the overall culinary chain. Zara told me that the guests often sit at the table reading all of the information printed on the menu about the resort, the owners, and the organic farm. The menu explains that much of the produce featured in the

\footnotetext{
${ }^{7}$ If the guests are on a daytime excursion, they will typically eat lunch off-site.
} 
restaurant comes directly from the farm and that other ingredients are "hand-picked" and locally sourced. Zara says that "when we tell them it's grown locally," tourists want to know more about where the food in the restaurant is actually grown. Regarding the salads, Zara says that the guests "can feel when they eat it that it's very organic. It's different. It's fresh." She says that tourists today are much more interested in knowing about their food than they were when she first started working there.

The kitchen at Pepem Nah is notable not only for the high quality of the food there, but because so many of the dishes have been invented by local chefs. Ian, who got his start as a chef when he worked as a cook for the British soldiers stationed in the jungle outside of San Antonio, enjoys the fast-paced environment of the kitchen, but he also loves the opportunity to create "something you want to make out of your mind...just to be creative." This autonomy, which has been shown to increase commitment to one's job and improve overall performance (see Gagne and Deci 2005), is not necessarily the norm. In many Belizean restaurants of this caliber, the kitchen is run by foreign-trained chefs who are often recruited from abroad (Spang n.d.). If, on the surface, the dishes themselves may not seem particularly 'authentic' (see Wilk 2006), the fact that they originated in the minds of local chefs suggests otherwise; everyone on staff who has had one of their creations become part of the menu - from the bartenders to the chefs and bakers - takes pride in these accomplishments, something that is often forgotten in neocolonial critiques of tourism.

It would be easy to overlook the role of the store room in this chain because it is located on the periphery of the resort, part of the backstage zone that most tourists will never see. However, this 3-person control center links not only the farm and the restaurant, but the farm and the many vendors who are not directly connected to the resort. After setting their menu for the 
week, the resort's kitchen staff gives the store room a list of ingredients they need. They consult with the head farmer who tells them what they can provide. Based on this feedback, the storeroom develops a shopping list for the employee who buys the ingredients that the farm cannot provide. This might include going to the butcher, buying dairy products from local Mennonites, or going to the market in San Ignacio for additional produce items, which may be grown locally or imported from Mexico.

The store room also manages the distribution of surplus produce. They send weekly emails to restaurants that have purchased from them in the past, announcing what they currently have on offer. They also field calls from restaurants looking for specific items like lettuce. Most of the purchasers are within a short drive of the storehouse, but produce can be also flown to outlying islands thanks to a nearby airstrip that accommodates small planes. Any excess produce that is not going to be used in the restaurant, the staff kitchen, or sold to other businesses will be offered for sale to resort employees and two intermediaries who sell produce at the San Ignacio market under their own names, not as agents of Pepem Nah.

\section{The Organic Farm}

Organic farming is not the norm in Belize. According to a report on the global status of organic farming at the turn of the $21^{\text {st }}$ Century, less than two percent of Belize's farmers were using organic methods (Willer and Kilcher 2009). Most organic production took place on cacao plantations in the southernmost district. ${ }^{8}$ Thus, resorts like Pepem Nah that highlight their organic produce are indeed remarkable within the context of Belize. The Pepem Nah organic

\footnotetext{
${ }^{8}$ Green \& Blacks signed an exclusive deal with the Toledo Cacao Growers' Association in the early 1990s for organically grown cacao; however, many other crops continue to be grown with pesticides.
} 
farm comprises 33 acres and is intended to showcase traditional, Maya horticultural techniques as well as modern, organic farming methods. Over the approximately 12 years that it has existed, however, it has shifted towards the latter. New installations like greenhouses and shade cloth have allowed the resort to produce a much greater variety of crops than have traditionally been grown in the area (e.g. eggplant, cucumbers, sweet peppers, and arugula). Though not visible from the road that connects the resort and the highway, the farm is only about a mile from the resort and can be reached via a dirt track that branches off the main road or a footpath. Guests are welcome to tour the farm with a guide and will typically come on horseback or in a utility vehicle (e.g. a Kawasaki Mule). If guests come during working hours, they will see the farmers but not necessarily interact with them. In some cases, particularly with small groups of guests, the farmers may be invited to share a small bit of information, but it is clear that everyone considers their role to be in agriculture, not tourism.

Lettuce, which emerged in the course of my research as centrally important, has only been grown here for five years. The farmers use the generic term 'lettuce' to refer to all manner of delicate leafy greens (e.g. mesclun) that ultimately wind up in the resort salads. Within the context of this resort's farm, they are typically not referring to iceberg lettuce. Lachlan explained to me that all of the varieties grown on the farm are delicate. Excess water during the rainy season poses problems for them as does the heat of the dry season. In other words, these are not plants that will grow without intentional care that is fine-tuned for the local growing conditions.

At the time of my research, the farm employed seven individuals, five of whom were related and live in San Antonio. None have college degrees and some had not completed high school. While three of the farmers had no experience in agriculture before being employed at the 
resort, even those who were experienced farmers had to learn new skills in order to grow the specific crops needed for the resort restaurant (e.g. lettuce) and to do so organically.

Plants that are indigenous to the region have many defenses against predators. The aforementioned chaya, for example, is so well protected that it grows like a weed in most peoples' yards. But despite Zara's efforts to get guests to eat chaya, there is still demand for other salad greens. Ian made this clear to me when he said that somedays the kitchen runs out of bowls because people are ordering so many salads. Consequently, the farmers must find ways to grow these crops, which are incredibly susceptible to the heat and tropical insects, using only organic farming techniques.

Twenty-nine-year-old Henry explained to me how hard it was for the farmers to learn how to grow organic lettuce. He has worked on this particular farm for 11 years and witnessed the entire five-year saga of fine-tuning their lettuce-growing techniques. Recalling the frustration of those early years when the plants were still being grown in full sun with no shade cloth, he said that the plants would seem to be doing okay, but then they would "go down" and the farmers were unable to figure out what went wrong. Lachlan, whose jocular, boots-in-the-mud management style allows him to deliver criticism without it coming across as too harsh, eventually came to the farmers and told them they really needed to figure out how to grow the lettuce better. So, they started experimenting.

After being told to "figure it out," the farmers planted one row of lettuce and tried one organic treatment, but it didn't work. So, they planted another row and tried a different treatment; it didn't work either. When they planted their third row, Henry suggested that they try something new. He wondered what would happen if they put chicken manure into a barrel, added water, and let it sit for 10-15 days before applying. Within four days of applying the solution to 
the lettuce plants, they could see a difference. I asked him what had given him that idea. He said they were using the dry manure on the cabbages, and they were doing great. But he knew they could not use the dry manure on the lettuce because the leaves are so much more delicate. He said the manure is hot and would burn the lettuce, but letting it soak in water for two weeks would make it safe to use on the lettuce.

This is not necessarily a novel invention - indeed, a quick Google search for 'chicken manure' and 'fertilizer' will yield instructions on how to make chicken manure fertilizer 'tea' by soaking the manure for approximately the same length of time that Henry did so as to neutralize the solution. Furthermore, despite the way Henry phrased his discovery as an independent invention, it is possible that they learned this method from an agronomy outreach service called Central Farm, whose extension officers periodically visit the resort.

Central Farm is a two-pronged institution - on one side of the Western Highway is the educational institution run by the University of Belize (UB) and on the other side is the statesponsored research and outreach facility. In the 1950s when Central Farm was established, its educators focused primarily on logging; its charge in the present day is to serve the approximately 50\% of Belizean residents who live in rural areas (Ministry of Agriculture 2017). Students who enroll in UB's agricultural program at Central Farm will gain exposure to agribusiness principles as well as practical experience in the fields, micro-propagation lab, etc. According to the head administrator, $90 \%$ of these students come from rural areas.

The extension officers on the governmental side of Central Farm are more focused on "the transfer of technology to farmers" (Ministry of Agriculture 2017). Though they often engage in information exchange with agronomists from abroad, this is a Belizean institution with local workers. Extension offers are expected to "[o]rganize and conduct training for farmers 
through farm visits, seminars, workshops, demonstrations, field trips and meetings." It is within this capacity that the extension officers visit Pepem Nah. However, they also learn from the local farmers, and extension interns are sometimes placed at Pepem Nah to learn directly from working with Henry and the others.

The example of the chicken manure tea epitomizes what happens in the agro-tourism contact zone. Tourist demands create a problem that must be solved by farmers, who creatively utilize the resources available to them, including externally created and disseminated knowledge, to adapt their production practices. Even if chicken manure fertilizer tea is a common technique in some parts of the world, it was new to these farmers, and they had to go through a process of trial and error before they knew how to make it work on this particular farm. Because the farmers at Pepem Nah remain in contact with these extension officers, who are in turn engaged in ongoing relationships with farmers throughout the district, this knowledge is further refined as it circulates throughout the local agricultural system.

The Village

As the previous sections have shown, the development of a market for certain kinds of products - locally sourced organic produce - has resulted in unique challenges and opportunities for the people who work at eco-resorts. Yet the question remains as to how tourism is affecting agriculture beyond this one resort. Because so many employees come from the village of San Antonio, it is the ideal place to look for evidence of how local communities are being affected by farm-to-table restaurants and resorts. 
Residents themselves describe San Antonio as a Maya village, but at least one scholar argues that the area has experienced a high degree of acculturation (see Colas 2009). ${ }^{9}$ According to the 2010 census, San Antonio has 1,847 residents spread across 381 households (Statistical Institute of Belize 2013). Although this is a rough estimate, the Pepem Nah farmers told me that approximately $90 \%$ of the families in the village are engaged in some form of farming. Peanuts, grown for local consumption and export, are the most valuable commodity, but farmers also grow potatoes, yams, cassava, and carrots among other things. Some of this produce is kept for household use, but a good deal is also sold at the market in San Ignacio. Sometimes farmers will sell their own produce directly, but one individual from the village will often serve as an intermediary and sell on the behalf of several small farmers. A very small number of individuals consider themselves organic farmers even though there has not been, to date, a large market for organic produce (a point I will return to shortly).

Many farmers who work at resorts would like to be able to support themselves and their families as independent growers, but they choose to work in tourism for one of three main reasons: (1) They need a guaranteed salary to be able to make debt payments; (2) They want to be fully vested in the nation's social security program before taking a chance on their own farms/businesses; or (3) They do not have enough land of their own for independent farming to

\footnotetext{
${ }^{9}$ According to Colas (2009), most of the residents having converted to Christianity, which he takes as a sign of acculturation. There are strong Pentecostal and Catholic contingents within the community and many of my contacts from the village who work at Pepem Nah identify with the former. Collas also argues that the eclipse of Yucatec Maya by Spanish is another sign of acculturation; however, I have worked with residents that regularly speak Yucatec and am in contact with one young adult who is actively trying to revitalize the language. There are also at least two groups in town that are trying to preserve traditional culture, one through handicrafts and the other through agriculture. The customs they have preserved have certainly changed over time. Ian told me this was because things like festivals are a fun way to honor "the real Maya" and their heritage, but people do not necessarily believe in these old customs. However, a transformation in meaning should not be interpreted as a loss of identity.
} 
be a viable option. Ironically, some residents of San Antonio and the neighboring village of Cristo Rey no longer have land because they sold it to North American immigrants, who came to Belize because they see it as a bucolic paradise where they can live their farm-to-table philosophy.

A few years ago, I was chatting with a friend in San Antonio about the size of some of the peanut plantations I had seen from the road. I asked how people managed to tend such large plots of land. She said that people often hired their neighbors to assist with planting and harvesting, but, she mentioned almost off-handedly, many people now are working at tourist resorts and thus are not available to help out locally. The farmers at the resort I have written about here actually did continue to work on their neighbors' farms during planting season to make extra money, but my friend's comment nonetheless reveals a perception that the community is being shortchanged in some way by villagers leaving to work on resort farms. While my friend did not say this, the development of resort farms could be seen as a threat to the local economy - even if the laborers are themselves locals - because anything grown on site (e.g. cabbage) is then not being purchased from villager-owned farms.

Interaction with foreigners - whether tourists, resort owners, or immigrants - is also changing the way local community members think about organic farming. Though most of the farmers in San Antonio do follow conventional agricultural procedures, which include using chemical fertilizers as well as pesticides, the idea of organic agriculture is gradually catching on in the village. Ian told me that there are three organic farmers in the village, though my estimates suggest that there are more. Ian was effusive when describing their produce. Describing the sweet peppers they grow year-round in greenhouses, he said: 
"If they don't trim their [plants], it's going to keep growing, keep growing, and keep growing. I'm telling you man, it's crazy."

But he also says that "it's like kind of depressing" to see how hard they have to work, and how much they have to sacrifice to grow organically when they “don't usually have a market for it...And people won't pay the price for [organic produce]."

I asked Ian why they would put in the energy to farm organically if they weren't receiving a return on investment. He said "I don't know... they use it for their own consumption as well. It's better for the body." This idea of organic produce being healthier is common in the area, even if most people themselves do not grow or buy organic vegetables. The most common answer I was given for why people don't buy organic is the price, but now that more foreigners with disposable income are coming into the area - either as tourists or immigrants - the market for organic produce seems to be expanding. This, in turn, opens up new possibilities for people like Henry and Ian who have been socialized through their work at resorts into the desires and tastes of these foreign customers.

\section{Discussion}

Regardless of whether or not a tourist's primary purpose in visiting a location is food related, he or she must eat (see López-Guzmán and Sánchez-Cañizares 2012). Even those who are willing and interested in exploring local cultures through their palates tend to retain certain preferences and/or restrictions (e.g. vegetarian, vegan, pescatarian, Kosher, etc.). While a server might be able to entice their guests to try local greens like chaya, organic salads - when available - remain a popular option. Tourists may even think this constitutes 'eating local' if the produce 
is billed as having been grown in the general vicinity, regardless of how ill-suited some of those plants may be for the local environment.

Tourists' preference for salads with organically grown greens (other than iceberg lettuce) pushes farmers to develop new knowledge about their environment. A common critique of tourism is that locals are often put into the position of having to perform caricatures of themselves based on who tourists imagine them to be (see Bruner 2005). Typically, this is negative, like the hula being transformed into a titillating stage show devoid of its traditional meaning (see Desmond 2001). Tourists' desires are fulfilled even if they are out of sync with reality because there is a financial incentive to do so. The situation at Belizean resorts offers a curious twist on this phenomenon. In the case of eco-resort farmers, the mandate to grow crops organically (whether that derives from tourists' demands, resort owners' ideological commitments, or both) necessitates that farmers cultivate new forms of knowledge despite the availability of scientifically-derived products (i.e. fertilizers and pesticides) that could help crops like lettuce grow faster and easier in the local environment. Locals are reinventing themselves to fit tourists' expectations of what they will find in Belize, but in so doing are acquiring skills that they desire and in which they take pride.

In many parts of the world, farmers have been encouraged to abandon "folk wisdom" in favor of modern techniques advocated by technical experts and agronomy agents (see Scott 1998). Yet in the case I am discussing here, the tourists are actually the experts - or position themselves as such in the ways they craft their reviews of local culinary offerings. Whether or not they know anything about farming, they are more accustomed to consuming organic salad greens than are the Belizean farmers. Their expectation that Belize will be brimming with 'fresh' and 'local' (read organic) produce - and resort owners' willingness to meet these expectations - 
obscures the fact that many local agricultural practices are harmful to the environment, and that imported processed foods still carry prestige within Belize. ${ }^{10}$ This is the essence of the agrotourism contact zone. Local farmers learn about the desirability of organic produce from the tourists - often indirectly, with resort owners serving as a link between the two groups -and then invent and adapt agricultural techniques to align their farms with tourists' expectations.

Is it neocolonial for tourists to insist upon eating salads when there are other more local, sustainable, and dare I say 'authentic' alternatives? Perhaps. But in this case it may not necessarily be a bad thing. It does seem unlikely that tourists would be a vector for healthier eating, especially considering that most tourists in Belize come from the United States...a country with a rampant obesity epidemic. Nonetheless, tourists are creating a market for farmers like those described by Ian who have a personal commitment to organic farming but have been unable earn a fair wage for their sacrifices (see also Giampiccoli and Kalis 2012). Other farmers, like Henry, are learning new skills because of tourists' demands that will enable them to take advantage of these shifting market preferences even if they ultimately leave the resort and go into business for themselves.

\section{Conclusion}

In this article, I have used salad as a case study of how ideologies rooted in a particular social context affect local realities for those who live and work in an agro-tourism contact zone. In working to meet the requests of these guests, the farmers have opportunities to learn new

\footnotetext{
${ }^{10}$ Immigrants who were attracted by this romanticized idea of Belize being a bucolic paradise like some of my interlocutors - are often disenchanted when they discover the widespread use of chemical inputs. All is not lost, however, as the presences of these individuals is creating opportunities for organic farmers to sell their produce to the CSA, at the market, or to the growing list of restaurants and resorts that highlight such fare on their menus.
} 
skills; however, their educational labor is obscured because tourists tend to come to Belize with assumptions that (indigenous) farmers already use organic techniques and work in harmony with the environment. This can have material benefits for the farmers that adopt organic practices, enabling them to take advantage of an expanding local market for organic produce. It is also affecting the way they think about farming. Several of the farmers discussed here have shifted towards the use of organic techniques on their own lands in the village. These farmers may not be giving up rice and beans in favor of salad, but in the process of learning to grow organic greens for the tourist market, they are developing a new skill set and thinking critically about the relationship between chemical inputs and health.

Although anthropological studies of tourism often critique its neocolonial tendencies, to assume that serving salad is a form of capitulation to the market demands is an oversimplification of the complex interactions between host and guest that denies the pride that these individuals derive from their work. Wage labor is a means to an end, but even so, these workers are gaining access to educational opportunities that most would not be able to acquire. Even within the structures of power that are undeniably present in the tourism industry, members of the local community have exerted their agency and even found pleasure in their ability to meet the challenges posed by feeding hungry, hungry gringos.

\section{References Cited}

Adams, Kathleen. 2016. "Tourism and Ethnicity in Insular Southeast Asia: Eating, Praying, Loving and Beyond." Asian Journal of Tourism Research 1(1):1-28.

Bruner, Edward M. 2005. Culture on Tour. Chicago: The University of Chicago Press. 
Colas, Pierre Robert. 2009. "Language Loss and Pentecostalism: The Yucatec Maya of San Antonio, Belize, Cayo District." Ketzalcalli 1:3-17.

Desmond, Jane. 2001. Staging Hula: Bodies on Display from Waikiki to Sea World. Chicago: University of Chicago Press.

Fine, Ben, Michael Heasman, and Judith Wright. 2002. Consumption in the age of affluence: the world of food. London: Routledge.

Gagne, Marylene, and Edward L. Deci. 2005. "Self-determination Theory and Work Motivation." Journal of Organizational Behavior 26:331-362

Giampiccoli, Andrea and Janet Hayward Kalis. 2012. "Tourism, Food, and Culture: Communitybased Tourism, Local Food, and Community Development in Mspondoland." Culture, Agriculture, Food and Environment 34 (2): 101-123.

Gray, Margaret. 2014. Labor and the Locavore: The Making of a Comprehensive Food Ethic. Berkeley: University of California Press.

Guthman, Julie. 2003. "Fast Food/organic Food: Reflexive Tastes and the Making of 'Yuppie Chow." Social \& Cultural Geography 4 (1):45-58.

López-Guzmán, Tomás and Sandra Sánchez-Cañizares. 2012. “Culinary Tourism in Córdoba (Spain).” British Food Journal 114 (2):168-179.

Medina, Laurie Kroshus. 2003. "Commoditizing Culture: Tourism and Maya Identity." Annals of Tourism Research 30 (2): 353-68.

Medina, Laurie Kroshus. 1997. "Development Policies and Identity Politics: Class and Collectivity in Belize." American Ethnologist 24 (1): 148-69.

Ministry of Agriculture. 2017. "Extension - Agriculture." http://www.agriculture.gov.bz/extension-2/.

LeBesco, Kathleen, and Peter Naccarato. 2012. Culinary capital. London: Berg.

Pratt, Mary Louise. 1992. Imperial Eyes: Travel Writing and Transculturation. London: Routledge.

Scott, James C. 1998. Seeing Like a State: How Certain Schemes to Improve the Human Condition Have Failed. New Haven, CT: Yale University Press.

Spang, Lyra. n.d. Food, Identity and Tourism: The Quest for Cuisine in Belize. Unpublished book manuscript. 
Statistical Institute of Belize. 2013. "Population and Housing Census: Country Report 2010." Belmopan. http://sib.org.bz/wp-content/uploads/2017/05/Census_Report_2010.pdf.

Sundberg, Juanita. 2006. "Conservation Encounters: Transculturation in the 'Contact Zones' of Empire.” Cultural Geographies 13 (2):239-265.

Sutherland, Anne. 1998. The making of Belize: Globalization in the margins. Westport: Greenwood Publishing Group.

Wilk, Richard R. 2006. Home Cooking in the Global Village. Akron: Berg.

Wilk, Richard R. 1999. “'Real Belizean Food': Building Local Identity in the Transnational Caribbean." American Anthropologist 101 (2): 244-55.

Willer, Helga, and Lukas Kilcher. 2009. "The World of Organic Agriculture: Statistics and Emerging Trends 2009 FIBL-IFOAM Report.” Frick. http://www.organic-world.net. 